\title{
Educational Intervention Based on the Health Belief Model to Modify Risk Factors of Cardiovascular Disease in Police Officers in Iran: A Quasi-experimental Study
}

\author{
Mohsen Saffari ${ }^{1,2}$, Hormoz Sanaeinasab ${ }^{1,2}$, Hassan Jafarzadeh², Mojtaba Sepandi ${ }^{1,3}$, Keisha-Gaye N. O'Garo ${ }^{4}$, \\ Harold G. Koenig ${ }^{4,5,6}$, Amir H. Pakpour ${ }^{7,8}$ \\ ${ }^{1}$ Health Research Center, Life Style Institute, Baqiyatallah University of Medical Sciences Tehran, Iran; ${ }^{2}$ Health Education Department, Faculty of \\ Health, Baqiyatallah University of Medical Sciences, Tehran, Iran; ${ }^{3}$ Department of Epidemiology and Biostatistics, Baqiyatallah University of Medical \\ Sciences, Tehran, Iran; ${ }^{4}$ Department of Psychiatry and Behavioral Sciences, Duke University Medical Center, Durham, NC, USA; ${ }^{5}$ Department of \\ Medicine, King Abdulaziz University, Jeddah, Saudi Arabia; ${ }^{6}$ School of Public Health, Ningxia Medical University, Yinchuan, China; ${ }^{7}$ Social \\ Determinants of Health Research Center, Qazvin University of Medical Sciences, Qazvin, Iran; ${ }^{8}$ Department of Nursing, School of Health and \\ Welfare, Jönköping University, Jönköping, Sweden
}

Objectives: Police officers may be at a greater risk for cardiovascular disease (CVD) than the general population due to their highstress occupation. This study evaluated how an educational program based on the health belief model (HBM) may protect police officers from developing CVD.

Methods: In this single-group experimental study, 58 police officers in Iran participated in a 5-week intervention based on HBM principles. Outcomes included changes in scores on an HBM scale, time spent on moderate to vigorous physical activity (International Physical Activity Questionnaire), body mass index (BMI), blood lipid profile, blood glucose, and blood pressure. The intervention consisted of 5 HBM-based educational sessions. Follow-up was conducted at 3 months post-intervention. The paired $t$-test was used to examine differences between baseline and follow-up scores.

Results: All aspects of the HBM scale improved between baseline and follow-up $(p<0.05)$, except the cues to action subscale. Self-efficacy and preventive behaviors improved the most. BMI decreased from $26.7 \pm 2.9 \mathrm{~kg} / \mathrm{m}^{2}$ at baseline to $25.8 \pm 2.4 \mathrm{~kg} / \mathrm{m}^{2}$ at follow-up. All components of the lipid profile, including triglycerides, cholesterol, high-density lipoprotein, and low-density lipoprotein, showed significant improvements post-intervention. Blood glucose and blood pressure also decreased, but not significantly. Nearly $25 \%$ of participants who were not physically active at baseline increased their physical activity above or beyond the healthy threshold.

Conclusions: A relatively brief educational intervention based on HBM principles led to a significant improvement in CVD risk factors among police officers. Further research is needed to corroborate the effectiveness of this intervention.

Key words: Health education, Lifestyle, Cardiovascular disease, Behavior change, Risk factors, Iran

Received: March 28, 2020 Accepted: May 20, 2020

Corresponding author: Mohsen Saffari, PhD

Health Research Center, Life Style Institute, Baqiyatallah University of

Medical Sciences, Sheykh-Bahaei Street, Tehran 1435916471, Iran

E-mail:m.saffari@bmsu.ac.ir

This is an Open Access article distributed under the terms of the Creative Commons Attribution Non-Commercial License (https://creativecommons.org/licenses/bync/4.0/) which permits unrestricted non-commercial use, distribution, and reproduction in any medium, provided the original work is properly cited.

\section{INTRODUCTION}

Cardiovascular disease (CVD), which has been recognized as a major cause of mortality and morbidity around the world [1], includes disorders such as hypertension, coronary heart disease, atherosclerosis, and stroke that involve pathologies of the heart and blood vessels [2]. Nearly 18 million people died from CVD in 2016, accounting for one-third of all deaths at the 
global level [3,4]. CVD is also among the top 3 causes of deaths in both developed and developing countries [5]. Many risk factors for CVD are modifiable, since they are frequently rooted in an unhealthy lifestyle [6]. Inadequate physical activity (PA), poor diet (e.g., consuming fast, fatty, and salty foods rather than fish, vegetables, and fruit), cigarette smoking, and exposure to multiple daily stressors are important lifestyle-related factors that contribute to the development of CVD [7,8]. Being overweight or obese and related diseases such as diabetes and high blood pressure are strong risk factors for CVD, particularly among those with a family history of CVD [9].

Police officers must be healthy in order to perform their duties, which involve prevention and control of crime and the provision of security and peace for the population. These duties require that they pay attention to physical fitness and cardiovascular health. However, studies show that lifestyle behaviors related to CVD are prevalent among police officers, as in the general population [10,11]. Other risk factors such as sleep problems due to night shifts and the high stress involved in law enforcement make police officers increasingly susceptible to CVD [12]. The risk factors for CVD, including hypertension, dyslipidemia, and elevated body mass index (BMI), have been found to be more common in police officers than in the general population [13]. Varvarigou et al. [14] found that police officers were at a higher risk of sudden cardiac death than those involved in non-emergency types of occupations. Furthermore, in the past decade nearly $9 \%$ of fatalities among police officers in the United States (despite their relatively young age) were attributed to cardiovascular causes [15]. Evidence also suggests that other CVD risk factors, such as metabolic syndrome and cigarette smoking, are common among police officers [16]. Thus, an unhealthy diet, physical inactivity, job stress, smoking, and inadequate sleep increase the likelihood of developing CVD in police officers.

The most effective strategies for prevention and control of CVD are lifestyle changes such as following a healthy diet, engaging in regular PA, managing stress, and controlling weight [17]. However, many people may not be aware of how to engage in and maintain such behaviors or the benefits to their health status from doing so. According to the World Health Organization (WHO), health education is a combination of learning opportunities to help persons and communities improve their health literacy and life skills that lead to an enhancement of individual and community health [18]. There are several theoretical models on which successful health education in- terventions are based. A well-developed model may help researchers design an educational intervention intended to increase knowledge, improve attitudes, and increase the frequency of health behaviors of specific groups [19].

The health belief model (HBM), initially developed by Rosenstock et al. (1988), is one of the first models designed to explain how to change health behaviors and the psychological processes involved in such changes. The HBM is based on value expectancy theory, which provides insights on how individuals may be motivated to engage in healthy behaviors [20]. The main assumptions in this model are that individuals should become aware that they are susceptible to negative outcomes as a result of their unhealthy behaviors (perceived susceptibility), that the severity of these negative outcomes may be high (perceived severity), that there are helpful strategies to prevent or control these negative outcomes (perceived benefits), that there are only limited costs involved in adhering to healthy behavior (perceived barriers), that there are environmental cues or signals that lead to the adoption of healthy behaviors (cues to action), and that they have the ability to engage in healthy behavior (self-efficacy) $[19,20]$.

Applying the HBM has been shown to be effective in developing interventions to improve health behavior and it has been used in a number of areas, including nutrition education, oral health, PA, and prevention of osteoporosis [21-23]. However, to our knowledge, this theoretical framework has not yet been utilized to develop a health education program to prevent and control CVD risk factors in police officers. The current study, then, was intended to determine whether an educational intervention based on HBM principles would be effective in reducing modifiable risk factors for CVD through psychological processes and behavioral changes in police officers.

\section{METHODS}

\section{Design and Sample}

This single-group experimental study in police officers was conducted using a before-and-after analysis. Participants were recruited using a convenience sample from a police station located in Tehran, Iran. Data were collected between April and August 2018. The sample size was determined based on Rosner [24]'s formula to calculate the sample for before-after studies with the following parameters: $\alpha$ (two-tailed) $=0.05 ; \beta=0.20$; effect size $=0.40$; and $S(\Delta)=1.00$. Advertisements were used to 
invite officers to participate in a health education program designed to prevent CVD. Individuals meeting the inclusion criteria who registered for the initial assessment were invited to participate. The inclusion criteria were age 25-55 years old, having at least 2 years of employment as a police officer, and having at least 3 of the following CVD risk factors: $\mathrm{BMI} \geq 25 \mathrm{~kg} / \mathrm{m}^{2}$, triglyceride (TG) level $\geq 200 \mathrm{mg} / \mathrm{dL}$; total cholesterol $\geq 200 \mathrm{mg} / \mathrm{dL}$; high-density lipoprotein cholesterol (HDL-C) $<60 \mathrm{mg} / \mathrm{dL}$; lowdensity lipoprotein cholesterol (LDL-C) $>130 \mathrm{mg} / \mathrm{dL}$; fasting blood sugar (FBS) $\geq 101 \mathrm{mg} / \mathrm{dL}$; systolic blood pressure (SBP) $\geq 121 \mathrm{mmHg}$; diastolic blood pressure (DBP) $\geq 81 \mathrm{mmHg}$; and engagement in physical exercise of less than moderate $(>150$ $\mathrm{min} / \mathrm{wk}$ ) or vigorous ( $>75 \mathrm{~min} / \mathrm{wk}$ ) intensity. These criteria were based on previous studies of common CVD risk factors in the general population and military personnel $[25,26]$. Individuals were excluded if they had a diagnosis of coronary heart disease, were receiving medical treatment for heart or vascular disorders, had other chronic diseases such as diabetes, a history of severe psychological problems such as major depression or post-traumatic stress disorder, or a history of stroke/myocardial infarction or cardiovascular surgery. Measurements of all outcome variables were conducted at baseline and 3 months following the intervention (except for demographic information, which was obtained only at baseline).

\section{Measures}

\section{Demographics}

Information was collected on age, sex, marital status, military rank, years of police force service, chronic health problems (e.g., migraine headache, low back pain, and dyspnea), history of smoking before recruitment into the police force (smoking for police officers in Iran is forbidden), frequency of engaging in regular physical exercise (at least $30 \mathrm{~min} / \mathrm{d}$ ), family history of CVD, and previous training on engaging in a healthy lifestyle to prevent CVD.

\section{Health belief model scale}

Since there is no standard questionnaire to assess the beliefs of police officers based on the HBM to prevent CVD, the authors developed a multidimensional health belief model scale (HBMS) based on previously used measures [21-23,27]. First, prior scales using the HBM framework were identified. An initial pool of 44 items was obtained using this process. Items were categorized into 7 subscales including perceived susceptibility ( 6 items), perceived severity ( 7 items), perceived benefits ( 7 items), per- ceived barriers ( 6 items), cues to action ( 5 items), self-efficacy (7 items), and preventive behaviors (6 items). Next, an expert panel consisting of 2 health educators, 1 psychologist, 2 nurses, 1 epidemiologist, and 1 cardiologist examined all items in terms of their representativeness, relevance, and appropriateness. Because of overlap between items and lack of relevance to the target group, 9 of the 44 items were removed or integrated into similar items. The final 35 items in the scale were categorized into the following subscales: perceived susceptibility (4 items), perceived severity ( 5 items), perceived benefits ( 6 items), perceived barriers ( 6 items), cues to action ( 3 items), self-efficacy ( 6 items), and preventive behaviors ( 5 items). The scale was then pilot-tested among 15 police officers who were not in the experimental group. Based on this pilot study, minor changes were made to some items to improve clarity and readability. The HBMS has an item response format that ranges from completely disagree (0) to completely agree (4). After reverse scoring of the 8 negative items, the scores of individual subscale items are summed and then divided by the number of items in the subscale. Thus, each subscale has a score ranging from 0 to 4, with higher scores indicating better awareness, attitudes, and behaviors. The test-retest reliability of the scale was examined, and it was found that the scale was stable over a 2-week period in 15 police officers $(r=0.88)$. The HBMS was developed in Persian (a translation of the scale into English is provided in the Supplemental Material 1).

\section{Modifiable risk factors}

Height and weight were measured by a trained nurse using a wall-mounted height meter (SECA-206, Hamburg, Germany) and digital weight scale (Beurer-PS160; Beurer GmbH, Ulm, Germany) to compute BMI. SBP and DBP were measured in the sitting position on 3 consecutive days by a nurse using a mercury sphygmomanometer (ALPK2-300V; Tanaka Sangyo Co., Tokyo, Japan). The mean of these measurements both before and after the intervention was used in this study. The first 4 items of the short form of the International Physical Activity Questionnaire (IPAQ) were used to determine the amount of time (minutes) spent on moderate PA (e.g., carrying light loads, bicycling at a regular pace, doubles tennis) to vigorous PA (e.g., heavy lifting, digging, aerobics, or fast bicycling) during the past 7 days [28]. Laboratory tests obtained included serum TG, total cholesterol, HDL-C, LDL-C, and FBS using standard protocols. 


\section{Intervention}

The education program was a group intervention consisting of 1.5-hour face-to-face sessions held weekly over 5 weeks in groups consisting of 8-12 participants. The first session focused on perceived susceptibility. The session started with a report on the statistics of CVD around the world, in the region (Middle East), in the country (Iran), among military personnel, and among police officers in particular. The unhealthy behaviors of those at high risk for CVD were also presented. In session 2, perceived severity was the focus. A documentary video describing complications and negative outcomes related to poor health behaviors affecting CVD was presented. In this video, patients with CVD were interviewed about the negative aspects of their lives and the difficulties they experienced engaging in activities of daily living because of CVD. After this video, participants were asked about how they might be at risk of such complications and negative outcomes due to their current health behaviors related to CVD.

Session 3 emphasized the perceived benefits of preventive behaviors and a healthy lifestyle. Using a focus group discussion format, participants were invited to share their viewpoints on healthy behaviors conducive to preventing CVD. For example, they discussed how following a healthy diet or having a plan for performing regular PA could help their physical and mental health and how a healthy lifestyle may help to prevent CVD. In addition, a health educator provided information on how healthy behaviors at different ages could reduce the risk of CVD. Healthy behaviors such as regular PA and consumption of a healthy diet were explained and ways to engage in them were suggested. Session 4 involved perceived barriers. To address this construct, brainstorming was conducted where participants were asked about barriers or difficulties that they might face when attempting to engage in CVD-related preventative health behaviors. Potential solutions were also discussed as ways of overcoming the barriers. The most practical methods of overcoming barriers were then ranked by participants, and participants were encouraged to use these solutions. In addition, a number of successful people who had overcome barriers to a healthy lifestyle shared their achievements with others.

Session 5 was designed to improve cues to action and increase self-efficacy. To enhance self-efficacy, 2 role models (police officers who were in excellent physical health and had positive attitudes toward maintaining physical fitness) presented lectures to the group on personal lifestyle planning and then took questions from the group. In addition, there was a discussion of how to break down health behaviors into small activities so that they could be more easily engaged in. To improve cues to action, participants were registered in a virtual network channel that delivered weekly reminders regarding health behaviors to prevent CVD. A gift keychain with a logo emphasizing a healthy heart was given to participants to remind them to engage in a healthy lifestyle.

\section{Statistical Analysis}

Data were analyzed using SPSS version 20 (IBM Corp., Armonk, NY, USA). To present quantitative data, the means and standard deviations (SD) were calculated; for categorical data, numbers and percentages were provided. The normality of the scaled data was assessed using the Shapiro-Wilk test. When the $p$-value was not significant $(>0.05)$, a normal distribution was assumed. Determining changes from baseline to follow-up was performed using the paired-sample $t$-test. The percentage of participants who were at risk in terms of modifiable cardiovascular risk factors based on cut-points suggested by laboratory reference ranges and international guidelines was compared between baseline and follow-up using a bar chart. An alpha level of less than 0.05 was considered to indicate statistical significance.

\section{Ethics Statement}

The study protocol was approved by the Institutional Review Board of Baqiyatallah University of Medical Sciences. The objectives and procedures of the study were explained to all participants and written informed consent was obtained.

\section{RESULTS}

The mean age of participants was $35.5 \pm 4.4$ years and the majority were male (79.3\%). More than two-thirds of the participants were married and had college or higher education level. Approximately $75 \%$ of the police officers had been enlisted in the military, and their average length of military service was $13.4 \pm 3.2$ years. Nearly $80 \%$ of subjects did not have any chronic illnesses and only 5 (8.6\%) reported a history of smoking before employment in the police force. More than half of the police officers who participated in the study did not engage in regular physical exercise (at least 30 minutes of mild to moderate PA) and about one-third reported they had participated in an educational program on healthy lifestyles to 
Table 1. Sample characteristics $(n=58)$

\begin{tabular}{|c|c|}
\hline Characteristics & n (\%) \\
\hline \multicolumn{2}{|l|}{ Age (y) } \\
\hline$<35$ & $36(62.1)$ \\
\hline$\geq 35$ & $22(37.9)$ \\
\hline \multicolumn{2}{|l|}{ Sex } \\
\hline Male & 46 (79.3) \\
\hline Female & $12(20.7)$ \\
\hline \multicolumn{2}{|l|}{ Marital status } \\
\hline Single & $17(29.3)$ \\
\hline Married & $39(67.2)$ \\
\hline Separated or divorced & $2(3.5)$ \\
\hline \multicolumn{2}{|l|}{ Education } \\
\hline High school & $7(12.1)$ \\
\hline Some college & $19(32.7)$ \\
\hline College or higher & $32(55.2)$ \\
\hline \multicolumn{2}{|l|}{ Rank } \\
\hline Enlisted & $43(74.2)$ \\
\hline Field officer & $15(25.8)$ \\
\hline \multicolumn{2}{|l|}{ Time of service (y) } \\
\hline$<10$ & $18(31.1)$ \\
\hline$\geq 10$ & $40(68.9)$ \\
\hline \multicolumn{2}{|l|}{ Chronic disease } \\
\hline Yes & $11(19.0)$ \\
\hline No & $47(81.0)$ \\
\hline \multicolumn{2}{|c|}{ Smoked prior to police recruitment } \\
\hline Yes & $5(8.6)$ \\
\hline No & $53(91.4)$ \\
\hline \multicolumn{2}{|l|}{ Exercised routinely } \\
\hline Yes & $27(46.5)$ \\
\hline No & $31(53.5)$ \\
\hline \multicolumn{2}{|c|}{ Family history of cardiovascular disease } \\
\hline Yes & $9(15.5)$ \\
\hline No & $49(84.5)$ \\
\hline \multicolumn{2}{|l|}{ Previous training' } \\
\hline Yes & $17(29.3)$ \\
\hline No & 41 (70.7) \\
\hline
\end{tabular}

${ }^{1}$ Attending educational programs on healthy lifestyle and cardiovascular risk factor prevention.

prevent CVD (Table 1).

Table 2 describes the HBM constructs and preventive behaviors from baseline to follow-up. All subscales except for cues to action revealed significant improvements from baseline to follow-up. The changes in some subscales, such as perceived susceptibility, perceived benefits, self-efficacy, and preventive behaviors, were greater than the other subscales $(p<0.001)$. Although perceived severity showed a significant change, the
Table 2. Scores on the health belief model domains and preventive health behaviors at baseline and 3 months following the intervention

\begin{tabular}{lccc}
\hline Constructs & $\begin{array}{c}\text { Baseline } \\
(\mathbf{n}=\mathbf{5 8})\end{array}$ & $\begin{array}{c}\text { Follow-up } \\
(\mathbf{n}=\mathbf{5 7 )}\end{array}$ & $\begin{array}{c}\text { Comparison } \\
(\boldsymbol{p} \text {-value) }\end{array}$ \\
\hline Perceived susceptibility & $2.55 \pm 0.39$ & $3.30 \pm 0.29$ & $<0.001$ \\
Perceived severity & $3.01 \pm 0.32$ & $3.36 \pm 0.24$ & $<0.05$ \\
Perceived benefits & $3.04 \pm 0.38$ & $3.60 \pm 0.27$ & $<0.001$ \\
Perceived barriers & $2.52 \pm 0.25$ & $2.93 \pm 0.22$ & $<0.01$ \\
Cues to action & $2.62 \pm 0.30$ & $2.83 \pm 0.34$ & 0.148 \\
Self-efficacy & $2.35 \pm 0.27$ & $3.26 \pm 0.26$ & $<0.001$ \\
Preventive behaviors & $2.14 \pm .031$ & $2.98 \pm 0.29$ & $<0.001$
\end{tabular}

Values are presented as mean \pm standard deviation.

Table 3. Changes in cardiovascular risk factors from baseline to 3 months of follow-up after the intervention

\begin{tabular}{lccc}
\hline Risk factors & $\begin{array}{c}\text { Baseline } \\
(\mathbf{n}=\mathbf{5 8})\end{array}$ & $\begin{array}{c}\text { Follow-up } \\
(\mathbf{n}=\mathbf{5 7})\end{array}$ & $\begin{array}{c}\text { Comparison } \\
(\boldsymbol{p} \text {-value })\end{array}$ \\
\hline BMl $\left(\mathrm{kg} / \mathrm{m}^{2}\right)$ & $26.7 \pm 2.9$ & $25.8 \pm 2.4$ & 0.012 \\
Triglycerides $(\mathrm{mg} / \mathrm{dL})$ & $215.3 \pm 47.9$ & $185.4 \pm 36.8$ & $<0.001$ \\
Cholesterol $(\mathrm{mg} / \mathrm{dL})$ & $228.7 \pm 56.9$ & $202.7 \pm 50.7$ & $<0.001$ \\
HDL-C $(\mathrm{mg} / \mathrm{dL})$ & $41.1 \pm 7.2$ & $53.3 \pm 6.7$ & $<0.001$ \\
LDL-C $(\mathrm{mg} / \mathrm{dL})$ & $138.4 \pm 35.9$ & $121.8 \pm 32.8$ & $<0.001$ \\
FBS $(\mathrm{mg} / \mathrm{dL})$ & $103.6 \pm 33.7$ & $97.6 \pm 29.0$ & 0.089 \\
SBP $(\mathrm{mmHg})$ & $132.3 \pm 26.8$ & $126.2 \pm 24.9$ & 0.063 \\
DBP $(\mathrm{mmHg})$ & $85.1 \pm 19.7$ & $83.5 \pm 18.8$ & 0.235 \\
PA (min/wk) & & & \\
Moderate & $135.9 \pm 36.4$ & $155.9 \pm 42.3$ & $<0.001$ \\
Vigorous & $32.3 \pm 17.9$ & $55.7 \pm 19.5$ & $<0.001$ \\
\hline
\end{tabular}

Values are presented as mean \pm standard deviation.

$\mathrm{BMI}$, body mass index; HDL-C, high-density lipoprotein cholesterol; LDL-C, low-density lipoprotein cholesterol; SBP, systolic blood pressire; DBP, diastolic blood pressure; PA, physical activity.

change was smaller than for other subscales.

Changes in the modifiable risk factors for CVD from baseline to follow-up are presented in Nearly all measures improved. FBS and blood pressure (SBP and DBP) did not significantly decrease, although there were trends in that direction. BMI, TG, and total cholesterol levels all decreased, and HDL-Cl, time engaged in moderate PA and vigorous PA increased significantly (Table 3).

Based on the defined cut-points for CVD risk factors, a considerable number of those who were at high-risk at the beginning of the study (baseline) dropped into the low-risk category for numerous outcomes by 3 months after the intervention (follow-up) (Figure 1). For PA, more than $25 \%$ changed from the high-risk to the low-risk categories. For the remaining out- 


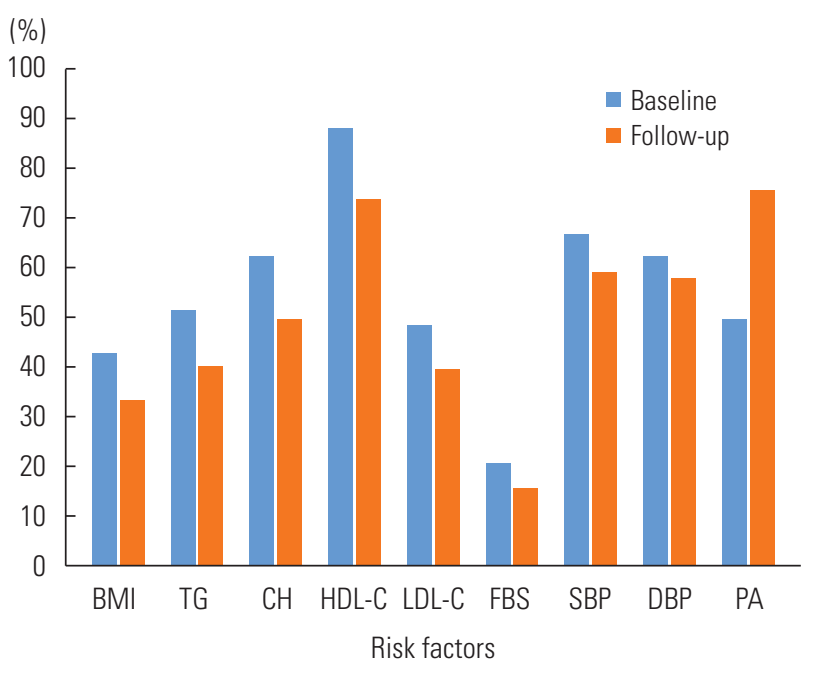

Figure 1. Changes in the percentage of high-risk participants in terms of cardiovascular risk factor categories from baseline to 3 months following the intervention. High-risk categories were the following: body mass index (BMI) $\geq 25 \mathrm{~kg} / \mathrm{m}^{2}$; triglycerides (TG) $\geq 200 \mathrm{mg} / \mathrm{dL}$; total cholesterol $(\mathrm{CH}) \geq 200 \mathrm{mg} / \mathrm{dL}$; high-density lipoprotein cholesterol (HDL-C) $<60 \mathrm{mg} / \mathrm{dL}$; lowdensity lipoprotein cholesterol (LDL-C) $>130 \mathrm{mg} / \mathrm{dL}$; fasting blood sugar (FBS) $\geq 101 \mathrm{mg} / \mathrm{dL}$; systolic blood pressure (SBP) $\geq 121 \mathrm{mmHg}$; diastolic blood pressure (DBP) $\geq 81 \mathrm{mmHg}$; low-risk category was: moderate (>150 $\mathrm{min} / \mathrm{wk}$ ) to vigorous (>75 min/wk) physical activity (PA).

comes, the percentage of participants with an HDL-C level less than $60 \mathrm{mg} / \mathrm{dL}$ decreased from 88\% to 73\% (a 15\% improvement). Category changes were least common for DBP and FBS ( $4 \%$ for DBP and $5 \%$ for FBS). The changes for the other variables were as follows: reduction in BMI, from $43 \%$ to $33 \%$ (10\% improvement); TG, from $52 \%$ to $40 \%$ (8\% improvement); total cholesterol, from $62 \%$ to $50 \%$ (8\% improvement); LDL-C, from $48 \%$ to $40 \%$ (8\% improvement); and SBP, from $67 \%$ to $60 \%$ (7\% improvement).

\section{DISCUSSION}

This study found that a relatively brief educational program based on the HBM may be effective in improving psychological and behavioral risk factors for CVD in police officers, including perceptions of their susceptibility to CVD, its severity, and the benefits of and barriers to preventive behaviors. In addition, self-efficacy for engaging in healthy behaviors increased as a result of the intervention. These improvements in awareness and attitudes led to changes in the lifestyle and healthrelated behaviors among the officers who were at risk for CVD.
However, reduction in indicators such as blood pressure and FBS may need a more comprehensive educational program than that administered in this study.

Only a limited body of research has examined the effectiveness of education programs on CVD risk factors. Wong et al. [29] conducted a randomized controlled trial to determine whether dietary counseling among individuals with grade 1 hypertension might be effective in reducing blood pressure, improving their lipid profile, and reducing BMI during a 1-year intervention. Participants were randomized to the intervention group (dietary counseling) or a control group (routine care and standard education). Although all outcome measures improved, no statistically significant between-group differences were found. The results are similar to the findings of the current study; however, the lack of a control group prevents us from attributing the changes to the intervention. There are other differences between the 2 studies. First, the degree of change in outcome variables in the present study was larger than that reported by Wong et al. [29]. This may be due to the multidimensional nature of the present study, which went beyond simple dietary recommendations. In the present intervention, participants were taught about other aspects of a healthy lifestyle, including the importance of PA and weight control. Furthermore, an established theoretical framework (i.e., the HBM) was used to develop the present educational program, which was shorter than that in the study conducted by Wong et al. [29] .

In another study designed to assess the impact of an intensive lifestyle intervention program on weight loss, PA, and reduction of caloric intake among individuals with type II diabetes, researchers reported significant improvements after 1 year in health outcomes (hypertension, hyperlipidemia, medical adherence) among those in the intervention group compared to those in the control group [30]. In a third study, a community-based weight management program, Graffagnino et al. [31] assessed the effectiveness of a program designed to help participants lose weight and reduce other CVD risk factors in 418 overweight or obese adults attending a community wellness center. They reported significant weight loss among 5-7\% of participants, as well as improvements in fasting lipids and fasting blood glucose. Thus, educational programs focusing on published treatment guidelines similar to the current intervention may be an effective strategy for weight loss and CVD risk factor improvement in a wide range of populations (including police officers). 
The present study also found in this convenience sample of police officers that more than half did not engage in the recommended levels of PA. This finding was confirmed when participants were categorized into those who engaged in an adequate amount of moderate to vigorous PA based on WHO guidelines [32]. Furthermore, this observation is similar to those reported in other studies of PA in police officers [33,34]. The present educational intervention was most effective in increasing PA in participants, with a more than $25 \%$ change from baseline among participants in the high-risk category to the low-risk category. This suggests that addressing PA in such programs may be one of the most important health behaviors that ultimately affects other CVD risk factors. In a study of adults in Chile, Cristi-Montero et al. [35] found that those who followed recommendations for moderate to vigorous PA had a lower likelihood of being overweight, having metabolic syndrome, diabetes, or hypertension than those who engaged in sedentary behaviors. However, the effect of PA among those with an elevated BMI may be larger than among those with normal BMI. Therefore, since the present program was conducted in participants with an average BMI above the normal range, it is important to replicate the current findings among those who are not overweight or obese and to assess the impact of PAs on other CVD risk factors. Educational interventions focused on increasing PA similar to ours have shown reductions in FBS and hypertension [36].

The present study did not have as great an effect on improving cues to action as it did on other psychological HBM domains. As Sharma and Romas [19] noted, among individuals whose perceived susceptibility and severity are low, stronger cues to action are needed to achieve more effective results. The low levels of these 2 HBM domains in the present sample may be why the cues to action domain did not change as much. The largest improvements were found in self-efficacy, indicating that one of the most important variables that may motivate individuals to improve healthy behaviors in order to reduce CVD risk factors is the degree of confidence that people have in their ability to make required lifestyle changes. Associations between self-efficacy and making healthy lifestyle changes have also been documented in prior studies $[37,38]$.

The intervention in the present study did not significantly reduce FBS or blood pressure. This may be due to 2 reasons. First, both measures were at borderline values (between the normal and abnormal ranges) at baseline. Thus, as reported in prior studies, further reductions in relatively normal values may be difficult $[26,31]$. Second, participants were followed for only 3 months after the intervention, and longer follow-up may have resulted in significant improvements in these risk factors as well. The present study did, however, find significant improvements in lipid profile, which is known to be a significant risk factor for CVD. These improvements may have been due to the dietary modifications and increases in PA that the intervention produced. Some intervention studies have not found that educational interventions were effective in reducing BMI $[39,40]$, whereas the present intervention did produce small, but significant, reductions in BMI and other CVD risk factors. This may be due to the different nature of the earlier interventions, as well as differences in the target group. Achieving physical fitness and reducing CVD risk factors may be particularly important for police officers given the duties that they must perform on their job.

\section{Limitations}

Several aspects of the present study may limit the generalizability of its findings. The first and foremost limitation is the absence of a control group. Despite improvements in the majority of outcomes, without a control group it is not possible to say whether the intervention actually produced these changes. However, the findings of this study may provide a basis for designing future studies with control groups to test the efficacy of HBM educational programs in reducing CVD risk factors. Second, police officers were only included if they had at least 3 predefined CVD risk factors. Thus, including individuals with other risk factors or those who lacked the CVD risk factors studied here may produce different results. Third, the present sample of police officers were a convenience sample of volunteers with considerable enthusiasm to participate in the study. Hence, studies that include officers who are less motivated to participate in such educational programs, particularly those who are mandated to do so, may produce different findings. Fourth, many other risk factors (e.g., psychological distress) may negatively affect cardiovascular health in police officers, although these were not assessed in the present study. Including measures of stress and anxiety, along with behavioral factors like those included here, in future studies may provide a better sense of the impact of educational interventions such as those analyzed here. Finally, we only followed the participants for 3 months after the intervention; therefore, long-term follow-up may produce different results. Nevertheless, because of these short-term results with promising findings, fu- 
ture studies are needed to determine whether the intervention has a long-term effect beyond 3 months.

In summary, a relatively brief 5-session educational intervention based on the HBM may serve to improve the attitudes and behaviors of police officers at high-risk for CVD. Application of this model in a less motivated sample of police officers without CVD risk factors to prevent their development may not be as effective as in the current intervention, warranting future randomized controlled trials in this and other populations. Such studies will provide important information on whether and how HBM-based educational interventions may help reduce the risk of CVD in police officers and other populations.

\section{SUPPLEMENTAL MATERIALS}

Supplemental material is available at https://doi.org/10. 3961/jpmph.20.095.

\section{CONFLICT OF INTEREST}

The authors have no conflicts of interest associated with the material presented in this paper.

\section{FUNDING}

None.

\section{ACKNOWLEDGEMENTS}

This study was conducted as a part of a master's degree program and funded by personal resources.

\section{AUTHOR CONTRIBUTIONS}

Conceptualization: MS, HS, HJ. Data collection: HJ. Formal analysis: MS, MS. Funding acquisition: None. Methodology: MS, HS, HGK. Project administration: MS. Writing - original draft: MS, HS, HJ, AHP. Writing - review \& editing: MS, HGK, KGNO, AHP.

\section{ORCID}

Mohsen Saffari https://orcid.org/0000-0001-7590-9516

Hormoz Sanaeinasab https://orcid.org/0000-0002-79945546
Hassan Jafarzadeh https://orcid.org/0000-0001-7822-0853

Mojtaba Sepandi https://orcid.org/0000-0001-6441-5887

Keisha-Gaye N. O'Garo https://orcid.org/0000-0001-91392596

Harold G. Koenig https://orcid.org/0000-0003-2573-6121

Amir H. Pakpour https://orcid.org/0000-0002-8798-5345

\section{REFERENCES}

1. Mensah GA, Roth GA, Fuster V. The global burden of cardiovascular diseases and risk factors: 2020 and beyond. J Am Coll Cardiol 2019;74(20):2529-2532.

2. Kaski JC, Kjeldsen KP. Cardiovascular pharmacotherapy: a new ESC handbook comprehensively addresses pharmacological treatment issues for patients with cardiovascular disease. Eur Heart J Cardiovasc Pharmacother 2019;5(4):185-186.

3. Joseph P, Leong D, McKee M, Anand SS, Schwalm JD, Teo K, et al. Reducing the global burden of cardiovascular disease, part 1: the epidemiology and risk factors. Circ Res 2017;121(6):677694.

4. Collaborators GBDEMRCD. Burden of cardiovascular diseases in the Eastern Mediterranean Region, 1990-2015: findings from the Global Burden of Disease 2015 study. Int J Public Health 2018;63(Suppl 1):137-149.

5. Teo KK, Dokainish H. The emerging epidemic of cardiovascular risk factors and atherosclerotic disease in developing countries. Can J Cardiol 2017;33(3):358-365.

6. Kim H, Kim S, Han S, Rane PP, Fox KM, Qian Y, et al. Prevalence and incidence of atherosclerotic cardiovascular disease and its risk factors in Korea: a nationwide population-based study. BMC Public Health 2019;19(1):1112.

7. Benson G, Sidebottom AC, Sillah A, Vock DM, Vacquier MC, Miedema MD, et al. Population-level changes in lifestyle risk factors for cardiovascular disease in the Heart of New Ulm Project. Prev Med Rep 2019;13:332-340.

8. Dennison RA, Feldman AL, Usher-Smith JA, Griffin SJ. The association between psychosocial factors and change in lifestyle behaviour following lifestyle advice and information about cardiovascular disease risk. BMC Public Health 2018;18(1):731.

9. Smail HO. The epigenetics of diabetes, obesity, overweight and cardiovascular disease. AIMS Genet 2019;6(3):36-45.

10. Alghamdi AS, Yahya MA, Alshammari GM, Osman MA. Prevalence of overweight and obesity among police officers in Riyadh City and risk factors for cardiovascular disease. Lipids Health Dis 2017;16(1):79. 
11. Baughman $P$, Fekedulegn $D$, Andrew ME, Joseph PN, Dorn JM, Violanti JM, et al. Central adiposity and subclinical cardiovascular disease in police officers. ISRN Obes 2013;2013:895687.

12. Ramey SL, Downing NR, Franke WD. Milwaukee police department retirees: cardiovascular disease risk and morbidity among aging law enforcement officers. AAOHN J 2009;57(11):448-453.

13. Tharkar S, Kumpatla S, Muthukumaran P, Viswanathan V. High prevalence of metabolic syndrome and cardiovascular risk among police personnel compared to general population in India. J Assoc Physicians India 2008;56:845-849.

14. Varvarigou V, Farioli A, Korre M, Sato S, Dahabreh IJ, Kales SN. Law enforcement duties and sudden cardiac death among police officers in United States: case distribution study. BMJ 2014;349:g6534.

15. Gendron P, Lajoie C, Laurencelle L, Trudeau F. Cardiovascular health profile among Quebec male and female police officers. Arch Environ Occup Health 2019;74(6):331-340.

16. Franke WD, Ramey SL, Shelley MC 2nd. Relationship between cardiovascular disease morbidity, risk factors, and stress in a law enforcement cohort. J Occup Environ Med 2002;44(12): 1182-1189.

17. Sarrafzadegan N, Mohammmadifard N. Cardiovascular disease in Iran in the last 40 years: prevalence, mortality, morbidity, challenges and strategies for cardiovascular prevention. Arch Iran Med 2019;22(4):204-210.

18. World Health Organization. Health education [cited 2020 Jul 7]. Available from: https://www.who.int/topics/health_education/en/.

19. Sharma M, Romas JA. Theoretical foundations of health education and health promotion. London: Jones \& Bartlett Learning; 2012, p. 145-148.

20. Glanz K, Rimer BK, Viswanath K. Health behavior and health education: theory, research, and practice. San Francisco: JosseyBass; 2008, p. 236-239.

21. Diddana TZ, Kelkay GN, Dola AN, Sadore AA. Effect of nutrition education based on health belief model on nutritional knowledge and dietary practice of pregnant women in Dessie Town, Northeast Ethiopia: a cluster randomized control trial. J Nutr Metab 2018;2018:6731815.

22. Hoseini H, Maleki F, Moeini M, Sharifirad GR. Investigating the effect of an education plan based on the health belief model on the physical activity of women who are at risk for hypertension. Iran J Nurs Midwifery Res 2014;19(6):647-652.

23. Parandeh L, Shafaie FS, Malakouti J, Mirghafourvand M, Asghari-Jafarabadi $M$. The effect of educational text message based on health belief model on osteoporosis preventive behaviors in women: a randomized controlled clinical trial. Women Health 2019;59(10):1128-1140.

24. Rozner B. Fundamentals of biostatistics. Belmont: Duxbury Press; 1995, p. 178

25. McGraw LK, Turner BS, Stotts NA, Dracup KA. A review of cardiovascular risk factors in US military personnel. J Cardiovasc Nurs 2008;23(4):338-344.

26. Sisti LG, Dajko M, Campanella P, Shkurti E, Ricciardi W, de Waure C. The effect of multifactorial lifestyle interventions on cardiovascular risk factors: a systematic review and meta-analysis of trials conducted in the general population and high risk groups. Prev Med 2018;109:82-97.

27. Tovar EG, Rayens MK, Clark M, Nguyen H. Development and psychometric testing of the health beliefs related to cardiovascular disease scale: preliminary findings. J Adv Nurs 2010; 66(12):2772-2784

28. Vasheghani-Farahani A, Tahmasbi $M$, Asheri $H$, Ashraf $H$, Nedjat S, Kordi R. The Persian, last 7-day, long form of the International Physical Activity Questionnaire: translation and validation study. Asian J Sports Med 2011;2(2):106-116.

29. Wong MC, Wang HH, Kwan MW, Fong BC, Chan WM, Zhang DX, et al. Dietary counselling has no effect on cardiovascular risk factors among Chinese grade 1 hypertensive patients: a randomized controlled trial. Eur Heart J 2015;36(38):2598-2607.

30. Redmon JB, Bertoni AG, Connelly S, Feeney PA, Glasser SP, Glick $\mathrm{H}$, et al. Effect of the look AHEAD study intervention on medication use and related cost to treat cardiovascular disease risk factors in individuals with type 2 diabetes. Diabetes Care 2010; 33(6):1153-1158.

31. Graffagnino CL, Falko JM, La Londe M, Schaumburg J, Hyek MF, Shaffer LE, et al. Effect of a community-based weight management program on weight loss and cardiovascular disease risk factors. Obesity (Silver Spring) 2006;14(2):280-288.

32. World Health Organization. Physical activity and adults: recommended levels of physical activity for adults aged 18-64 years [cited 2020 Jul 7]. Available from: https://www.who.int/ dietphysicalactivity/factsheet_adults/en/.

33. Vukovic M, Kukic F, Cvorovic A, Jankovic D, Prcic I, Dopsaj M. Relations between frequency and volume of leisure-time physical activity and body composition in police officers. Res Q Exerc Sport 2020;91(1):47-54.

34. Vancini RL, de Lira CA, Anceschi SA, Rosa AV, Lima-Leopoldo AP, Leopoldo AS, et al. Anxiety, depression symptoms, and physical activity levels of eutrophic and excess-weight Brazil- 
ian elite police officers: a preliminary study. Psychol Res Behav Manag 2018;11:589-595.

35. Cristi-Montero C, Steell L, Petermann F, Garrido-Mendez A, Diaz-Martinez X, Salas-Bravo C, et al. Joint effect of physical activity and sedentary behaviour on cardiovascular risk factors in Chilean adults. J Public Health (Oxf) 2018;40(3):485-492.

36. Dixon NC, Hurst TL, Talbot DC, Tyrrell RM, Thompson D. Effect of short-term reduced physical activity on cardiovascular risk factors in active lean and overweight middle-aged men. Metabolism 2013;62(3):361-368.

37. Blanchard C, Arthur HM, Gunn E. Self-efficacy and outcome expectations in cardiac rehabilitation: associations with women's physical activity. Rehabil Psychol 2015;60(1):59-66.

38. Losekam S, Goetzky B, Kraeling S, Rief W, Hilbert A. Physical activity in normal-weight and overweight youth: associations with weight teasing and self-efficacy. Obes Facts 2010;3(4): 239-244.

39. Torija Archilla A, Perez Gonzalez J, Sarmiento Ramirez A, Fernandez Sanchez E, Gonzalez Ruiz JR, Guisado Barrilao R. Effects of a recreational general physical activity program with short term and moderate intensity of blood pressure and other cardiovascular risk factors in hypertensive patients over 50 years old. Aten Primaria 2017;49(8):473-483 (Spanish).

40. Masa-Font R, Fernandez-San-Martin MI, Martin Lopez LM, Alba Munoz AM, Oller Canet S, Martin Royo J, et al. The effectiveness of a program of physical activity and diet to modify cardiovascular risk factors in patients with severe mental illness after 3-month follow-up: CAPiCOR randomized clinical trial. Eur Psychiatry 2015;30(8):1028-1036. 